\title{
Annual Progress Report
}

for DoE Grant No. DE-FG02-92ER12128

for the period December 1, 1992 - May 31, 1993

"Combustion Synthesis and Engineering of Nanoparticles for Electronic, Structural and Superconductor Applications"

Gregory C. Stangle (PI/PD), Vasantha R. W. Amarakoon (PI), and Walter A. Schulze (PI)

School of Ceramic Engineering and Sciences

New York State College of Ceramics at Alfred University

Alfred, New York 14802

May 28, 1993

\section{DISCLAIMER}

\begin{abstract}
This report was prepared as an account of work sponsored by an agency of the United States Government. Neither the United States Government nor any agency thereof, nor any of their employees, makes any warranty, express or implied, or assumes any legal liability or responsibility for the accuracy, completeness, or usefulness of any information, apparatus, product, or process disclosed, or represents that its use would not infringe privately owned rights. Reference herein to any specific commercial product, process, or service by trade name, trademark, manufacturer, or otherwise does not necessarily constitute or imply its endorsement, recommendation, or favoring by the United States Government or any agency thereof. The views and opinions of authors expressed herein do not necessarily state or reflect those of the United States Government or any agency thereof.
\end{abstract}

Submitted to:

U.S. Department of Energy

Chicago Field Office

Contracts Division

9800 South Cass Avenue

Argonne, Illinois 60439

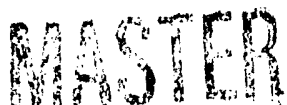




\section{NOTICE}

This report was prepared as an account of work sponsored by the United States Government. Neither the United States nor the Department of Energy, nor any of their employees, nor any of their contractors, subcontractors, or their employees, makes any warranty, express or implied, or assumes any legal liability or responsibility for the accuracy, completeness, or usefulness of any information, apparatus, product or process disclosed or represents that its use would not infringe privately-owned rights. 
Table of Contents

$\begin{array}{ll}\text { SUMMARY } & 1\end{array}$

I. INTRODUCTION 2

II. BACKGROUND 2

A. The Need for Nanocrystalline Materials 2

B. Existing Methods Used to Produce Nanocrystalline Materials 3

C. Commercial Potential of Existing Methods 4

D. The Present Approach 4

III. RESEARCH ACCOMPLISHMENTS MADE DURING THIS PERIOD 7

$\begin{array}{ll}\text { A. Material Selection } & 7\end{array}$

B. Synthesis of Yttria-Stabilized $\mathrm{ZrO}_{2}$

C. Fabrication of Dense Nanocrystalline $\mathrm{Y}_{2} \mathrm{O}_{3}$-Stabilized $\mathrm{ZrO}_{2}$ Parts 15

D. Prospects for Scale-up, Energy Savings, Commercialization Potential 19

IV. REFERENCES CITED 20

$\begin{array}{ll}\text { V. LIST OF PERSONNEL } & 21\end{array}$ 


\section{SUMMARY}

Fully dense, nanocrystalline ceramic articles were prepared by the new nanofabrication process that has been developed in this research program. The process consists of two steps: synthesis of ceramic nanoparticles and fabrication of dense, nanocrystalline ceramic parts. The synthesis step produced 10-nanometer-diameter crystallites, and is capable of being scaled up to kilogram/hour production rates. The fabrication step produced dense parts at significantly reduced sintering temperatures and times--representing a factor of 10 100 reduction in process energy requirements. The process was demonstrated by producing ultrafine-grained yttria-stabilized $\mathrm{ZrO}_{2}$, an important material with a variety of energy-related applications (e.g., solid electrolytes, oxygen sensors, electrode materials, thermal barrier coatings, etc.). Results from the first reporting period (12/92-5/93) clearly illustrate the capabilities of this energy-efficient and directly commercializable process for producing dense, nanocrystalline, multicomponent oxide ceramics. 


\section{INTRODUCTION}

This is the first annual progress report for the Department of Energy research grant no. DE-FG02-92ER12128, entitled Combustion Synthesis and Engineering of Nanoparticles for Electronic, Structural and Superconductor Applications. This report pertains to the period December 1, 1992 to May 31, 1993, and summarizes research accomplishments made during the period January 4, 1993 (the starting date of the first person hired for this research project) to May 31,1993. The overall objective of the program has been to conduct a comprehensive investigation of the synthesis, shapeforming and sintering of ultrafine ceramic particles--while simultaneously minimizing process energy consumption. This work was, of course, needed in order to prepare advanced materials with highly desirable nanocrystalline features for use in applications that require, e.g., dielectric, structural or superconducting ceramics.

In order to achieve this objective, a combined experimental and theoretical investigation is being conducted. The goal of the experimental portion is to quantitatively determine the role of key process parameters (such as the characteristics of the starting materials, synthesis and firing conditions, grain-boundary modification, etc.) on the resulting ultrafine-grained microstructure. The theoretical portion applies sound physicochemical principles to (i) provide a framework for the interpretation of experimental results, and (ii) develop a fundamental understanding of the combustion synthesis and fastfiring process steps with respect to the processing-microstructure-property relationship. The result is expected to be a fundamental understanding of a novel and important process for the production of compositionally complex nanoparticles and the fabrication of nanocrystalline materials that may be readily scaled-up to commercial production rates.

The three-year plan (12/92 - 11/95) calls for a thorough study of the synthesis, shape-forming, doping (as required) and sintering of three important advanced ceramic materials: yttria-stabilized $\mathrm{ZrO}_{2}$ (for structural applications and as oxygen sensors), $\mathrm{YBa}_{2} \mathrm{Cu}_{3} \mathrm{O}_{7-\mathrm{x}}$ (a high-temperature superconduc:or with uses, e.g., in magnetic flux trapping and high-speed capacitor applications), and $\mathrm{BaTiO}_{3}$ (for capacitor applicinons). The study during the first reporting period has focused primarily on the preparation of dense, nanocrystalline yttria-stabilized $\mathrm{ZrO}_{2}$, in order to illustrate the capabilities of this energy-efficient and directly commercializable process for producing dense, nanocrystalline ceramics materials.

\section{BACKGROUND}

\section{A. The Need for Nanocrystalline Materials}

The economic fabrication of nanocrystalline powders and materials with precisely controlled nanocrystalline microstructures is necessary to realize various applications of 
advanced materials. The ability to produce solids with new atomic arrangements and new properties is an important objective of commercial and national security concerns because of the significant impact these materials will have in improving the performance of, e.g., dielectric, structural and superconductor ceramic materials. 1,2 A prerequisite to the routine and cost-effective manufacture of optimal high-performance nanocrystalline materials is, of course, a fundamental understanding of the key factors influencing the fabrication process. Only then can high-quality, high-reliability and low-cost materials be expected to be available in relatively large quantities.

The realization of numerous important applications await the availability of sufficient quantities of such nanocrystalline powders, and the technical capability required to retain (by powder surface modification and careful sintering) the nanocrystalline features in a final, full-density piece. For example, in energy storage applications, magnetic fields up to $22.4 \mathrm{kOe}$ have been permanently trapped transversely to axes of hollow $\mathrm{Nb}_{3} \mathrm{Sn}$. superconducting cylinders. ${ }^{3}$ Similar fields could be trapped in ${ }^{2} \mathrm{Ea}_{2} \mathrm{Cu}_{3} \mathrm{O}_{7-\mathrm{x}}$ ceramics that have been processed with a controlled microstructure having flux pinning sites incorporated via the surface coating technique. Alternatively, in high-speed capacitor applications, the incorporation of an insulating intergrain phase of high resistivity and sufficient thickness, along with control of the final microstructure, allows for the development of high $K^{\prime}$ capacitors that are capable of operating at high frequencies. For high-temperature structural applications, the availability of nanocrystalline yttria-stabilized zirconia is expected to improve upon the material's already attractive mechanical and thermomechanical stability at elevated temperatures. Nanoscale microstructures in $\mathrm{BaTiO}_{3}$-based dielectrics will facilitate the next level of miniturization in multilayer devices. The reduced grain size also offers the possibilities of developing size-limited phenomena such as superparaelectricity.

\section{B. Existing Methods Used to Produce Nanocrystalline Materials}

The production of dense, nanocrystalline materials can generally be divided into two process steps: synthesis of nanoparticles, and fabrication of the dense, nanocrystalline material from these nanoparticles.

Nanoparticles can be produced by any one of several methods. ${ }^{4}$ Each method, however, typically suffers from extremely low production rates and undesirable particle cluster formation. Vacuum, gas-phase and liquid-phase processes produce nanoparticles and nanoparticle clusters by generalized solution-precipitation and chemical reaction mechanisms, but are characteristically slow and both energy and capital intensive (i.e., expensive) processes. Particle size reduction to form nanoparticles has been applied in some cases, but has been successful in a very limited number of cases. Few existing 
fabrication techniques can routinely produce multicomponent oxide ceramic nanoparticles, which of course includes the bulk of important advanced ceramic materials.

Nanocrystalline materials are typically produced from nanoparticles using routine sintering and/or hot pressing approaches. ${ }^{5}$ The goal, of course, is to produce dense parts (by sintering to remove porosity) without losing the hard-won nanocrystallinity in the process. Two mechanisms operate in parallel during the sintering process. First, the elevated sintering temperature increases mass diffusion rates that in turn increase the rate at which porosity is eliminated. Second, at sintering temperatures, the nanoparticles may coarsen at very rapid rates, as a result of the high surface energy that results from the nanoparticle's extremely high surface curvature. The following trade-off is nearly always observed: fine-grained parts with significant porosity, or low-porosity parts with grains that are no longer nanocrystalline. It is often the case that the benefits of producing particles with nanometer-sized features are lost when the nanoparticles are used to make fully dense ceramic materials.

\section{Commercial Potential of Existing Methods}

The principal feature that a nanoparticle fabrication process must possess for commercial application is its potential for scale-up. A second would be economically reasonable capital and operating (particularly, energy) costs. A third would be its breadth of application--that is, to produce a wide variety of materials without significant process modifications. Unfortunately, most of the existing nanoparticle formation processes are simply laboratory-scale processes, producing nanogram to milligram quantities of the target material. The most plausible, practical reason for this is the highly "dilute" nature of each of the processes that is necessary to limit the size of both primary particles and particle clusters. Moreover, many of the processes use specialized equipment that is expensive to purchase, operate and maintain. Reactor volumes are typically small, and useful, practical guidelines for scale-up to commercial production rates do not yet appear to be firmly established. Finally, many of the processes appear to be applicable to the production of a relatively small number of compounds, and even fewer have been applied to the synthesis of multicomponent (e.g., binary or ternary metal oxide) compounds. Taken together, it does not appear that a simple, relatively inexpensive, high-volume, widely applicable process currently exists for the production of nanoparticles of "complex" composition.

\section{The Present Approach}

The present approach to producing nanocrystalline materials is divided into two sub-processes: synthesis of nanoparticles using a combustion synthesis process, and fabrication of dense, nanocrystalline ceramic articles. The method is demonstrated for multicomponent oxide ceramics--that is, for materials of general composition $(A, B) O$ and 
$(\mathrm{A}, \mathrm{B}, \mathrm{C}) \mathrm{O}$, where $\mathrm{A}, \mathrm{B}$ and $\mathrm{C}$ are cations--which are difficult or impossible to produce by other methods.

The nanoparticle synthesis process relies on the principles of propellant technology: a fuel is mixed with an oxidizer; the mixture is ignited; and the burning mixture generates a great deal of heat and gas in a short period of time. [In fact, some of the rocket fuel compositions that were developed in the Gemini and Apollo programs are analogous to the precursor mixture compositions used in this work. $\left.{ }^{6}\right]$ This nanoparticle synthesis process uses the heat generated by the chemical reaction between fuel and oxidizer to convert the precursor mixture to the target ceramic material. This nanoparticle synthesis process also uses the rapid generation of gas (from the rapid decomposition of precursor material) as a means to yield very finely divided ceramic particles.

The synthesis process itself is conducted in two steps: (i) formation of fine precursor mixture powders from a molecularly mixed precursor solution, and (ii) conversion of the precursor mixture powders to ultrafine particles by a combustion synthesis. See Fig. 1. In the first step, aqueous solutions of precursor metal salts and a suitable, water-soluble fuel are prepared for use in the precursor mixture powder preparation apparatus. Two apparatuses are used in this study: an aerosol spray pyrolysis unit, and a table-top spray drying unit. Results from using the two apparatuses may subsequently be compared. The precursor mixture powder produced in this step is then available for use in the second nanoparticle synthesis process step.

The second step of the proposed nanoparticle production process requires the combustion of the precursor mixture powders--which at this point consist of an explosive mixture whose composition is strictly analogous to that of gunpowder--to form nanoparticles of the target material. Upon rapid heating, a highly exothermic and rapid chemical reaction occurs that (i) raises the particle's temperature, causing formation of the target ceramic material to take place, and (ii) generates a large amount of gas that leads to nearly instantaneous disintegration of the precursor particle as the nanoparticles are formed. The molecular mixing of the precursors and its retention upon rapid drying of the precursor-solution droplets ensure that the length scale of homogeneity (and thus diffusion distances) in the reacting particle are small. Chemical homogeneity in the product nanoparticles is also expected to be retained at this length scale. In addition, the organic fuel material essentially assumes a role as space-filling template that determines the size distribution and topology of the pore structure of the reacted precursor particle (that would be present in the absence of particle disintegration). This grenade/shrapnel scenario can 


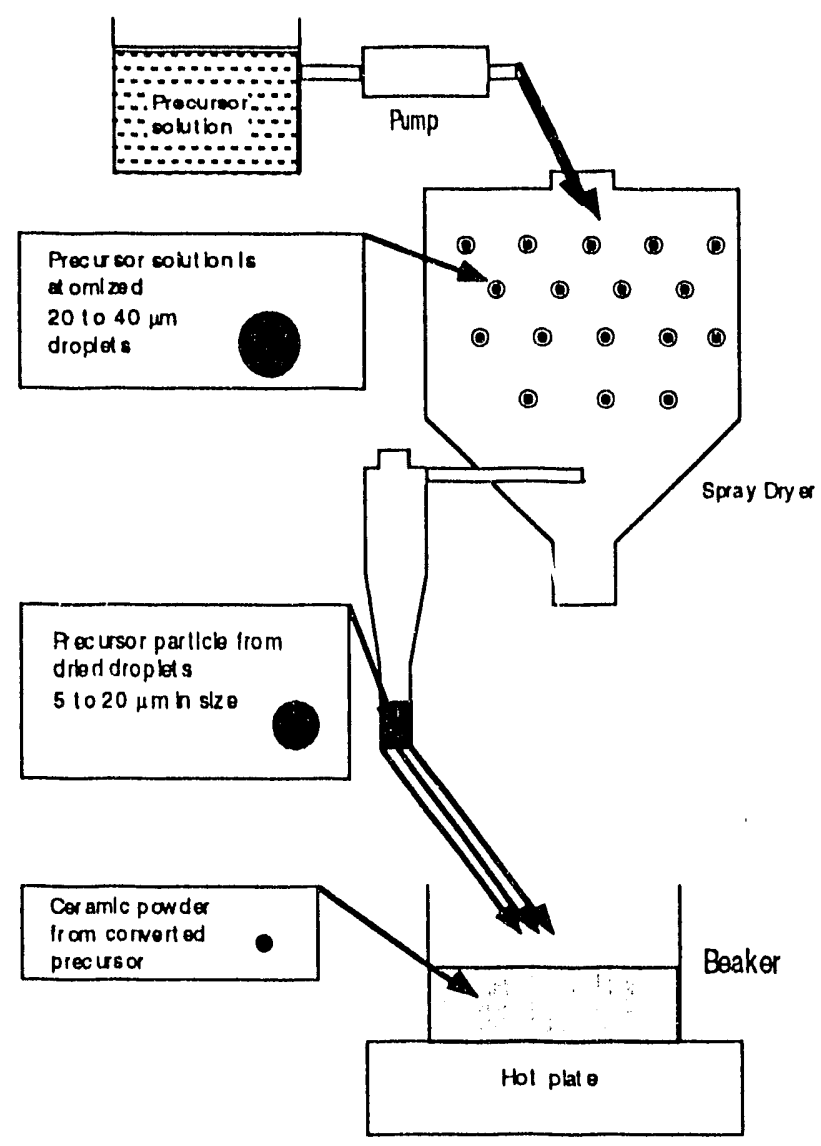

Figure 1. Schematic representation of the combustion synthesis process.

thus be expected to significantly reduce the size of the as-collected precursor powder.

The final step in successfully fabricating dense, nanocrystalline materials requires that sintering and densification be conducted without losing the nanometer-sized features through (undesirable) grain-growth processes that usually occur. Fast-firing, a relatively nonconventional approach to firing and densifying ceramic materials is used. Fast-fire processing uses heating rates above $100^{\circ} \mathrm{C} / \mathrm{min}$, uses significantly reduced sintering temperatures, and sintering times of several minutes (and often as low as one minute). ${ }^{7}$ Low-porosity, nanocrystalline ceramic materials have been successfully fabricated in this way. This remarkable behavior may be understood in the following way. First, in many systems the densification process has a much higher activation enthalpy than grain growth. Second, the nanocrystalline materials possess a high surface curvature, which gives rise to a very high surface energy. Fast-firing takes advantage of the high energy that 
nanoparticles possess, in order to accelerate the elimination of porosity by sintering. Simultaneous grain growth can be suppressed if the furnace temperature is increased quickly to a temperature where densification can progress more rapidly that grain growth. Once nearly full density is reached, still lower sintering temperatures can be considered for further microstructural control and limited grain growth. In addition, the use of sintering additives and/or grain growth inhibitors (i.e., carefully controlled grain boundary engineering) is expected to enhance the degree of success of this final process step.

\section{RESEARCH ACCOMPLISHMENTS MADE DURING THIS PERIOD}

\section{A. Material Selection}

Work performed during the first reporting period was restricted to the preparation of dense, nanocrystalline yttria-stabilized $\mathrm{ZrO}_{2}$, in order to illustrate the capabilities of the process during the abbreviated performance period. The choice of "doped" $\mathrm{ZrO}_{2}$ is a judicious one, for two reasons. First, a large number of important applications have been suggested for $\mathrm{ZrO}_{2}$-based materials to which a relatively small amount of, for example, $\mathrm{Y}_{2} \mathrm{O}_{3}, \mathrm{MgO}$, or $\mathrm{CaO}$ have been added. A handful of representative examples are listed in Table 1. [The energy-related applications are particularly significant.] Second, preparation of doped $\mathrm{ZrO}_{2}$ parts by this process clearly illustrates the capabilities of this energyefficient and directly commercializable process for producing dense, nanocrystalline, multicomponent oxide ceramics.

\section{B. Synthesis of Yttria-Stabilized $\mathrm{ZrO}_{2}$}

The synthesis process was conducted in three steps: (i) preparation of a molecularly mixed solution containing dissolved fuel and oxidizer materials, (ii) formation of precursor mixture particles from the precursor solution, and (iii) conversion of the precursor particles to the target ceramic :iaterial by combustion synthesis. In all cases, the precursor solution was an aqueous solution, to which yttrium nitrate hexahydrate

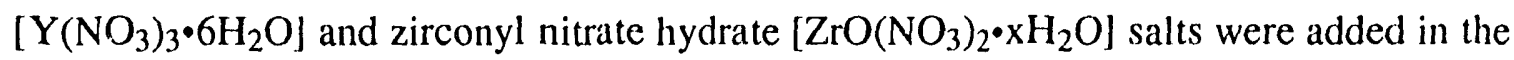
$\mathrm{Y}: \mathrm{Zr}$ ratio of 4:96. The total concentration of dissolved salts was maintained at $0.1 \mathrm{~mol} / \mathrm{L}$. Several fuel materials were screened for their effectiveness in producing finely divided ceramic material in subsequent process steps.

Precursor particle formation was conducted using either an aerosol spray pyrolysis unit or a benchtop spray drier. Figures 2 and 3 show representative SEM photomicrographs of the aerosol-derived and spray-dried precursor mixture particles, respectively. It may be observed in both figures that dense, uni- or weakly agglomerated, spherical particles of the precursor mixture were produced. "these precursor particles were found to possess the same composition as the starting precursor solution. This indicates that this process step avoids the long-range phase segregation that is commonly found in 
numerous other processes for preparing multicomponent metal oxide particles. It also indicates that the precursor solution's high degree of mixing is preserved--a condition that is crucial to the success of the subsequent combustion synthesis process step.

Table 1. Representative Applications for "Doped" $\mathrm{ZrO}_{2}$ Materials.

\begin{tabular}{|c|c|}
\hline General Application & Examples \\
\hline Heating elements & Oxidizing atmosphere, $1500-2500^{\circ} \mathrm{C}$ \\
\hline Cathode material & Air plasma torches \\
\hline Electrode material & $\begin{array}{l}\text { Energy conversion } \\
\text { - Magnetohydrodynamic (MHD) devices } \\
\text { - Magnetogasdynamic (MSD) devices }\end{array}$ \\
\hline Oxygen sensors, oxygen pumps & $\begin{array}{l}\text { Combustion chambers } \\
\text { Steelmaking processes } \\
\text { Automotive applications }\end{array}$ \\
\hline Solid electrolytes & Fuel cells \\
\hline Electrode material & $\begin{array}{l}\text { Energy storage } \\
\text { - Hi-temp thermolysis of } \mathrm{H}_{2} \mathrm{O}->\mathrm{H}_{2}\end{array}$ \\
\hline High-temperature pH "meter" & Hydrothermal solutions, geothermal brines \\
\hline Other & $\begin{array}{l}\text { Thermal barrier coatings } \\
\mathrm{ZrO}_{2} \text { fibers for thermal insulation } \\
\text { Molds for Ti-casting (dental restoratives) } \\
\text { Membranes } \\
\text { Transformation-toughened ceramics } \\
\text { Advanced ceramic composites }\end{array}$ \\
\hline
\end{tabular}

Conversion of the precursor particles to the target ceramic material was accomplished in remarkably straightforward manner--using equipment that is simple and inexpensive to purchase, operate and maintain. Small amounts of the dry (gunpowder-like) precursor mixture powcler were ignited--in air--when they were rapidly placed in contact with a heated surface. The heated surface was maintained at a temperature that fell in the range of $250-450{ }^{\circ} \mathrm{C}$ (as measured by an optical pyrometer). Once ignited, the fueloxidizer mixture typically reacted to completion in less than one second. In this initial set of experiments, the heated surface was simply a Pyrex beaker that had been placed upon a laboratory hot plate maintained at the appropriate temperature. The precursor mixture powder was then poured into the preheated beaker, which also served to contin in the product powder.

The composition of the product material was shown to be fully converted from the precursor to the target ceramic material. Figure 4 shows the $x$-ray diffraction (XRD) patterns for samples prior to and following ignition. The patterns show that an essentially amorphous mixture of fuel and oxidizer was converted to a well-defined crystalline solid. Further, the process was shown to produce a single-phase product. Figure 5 shows the 


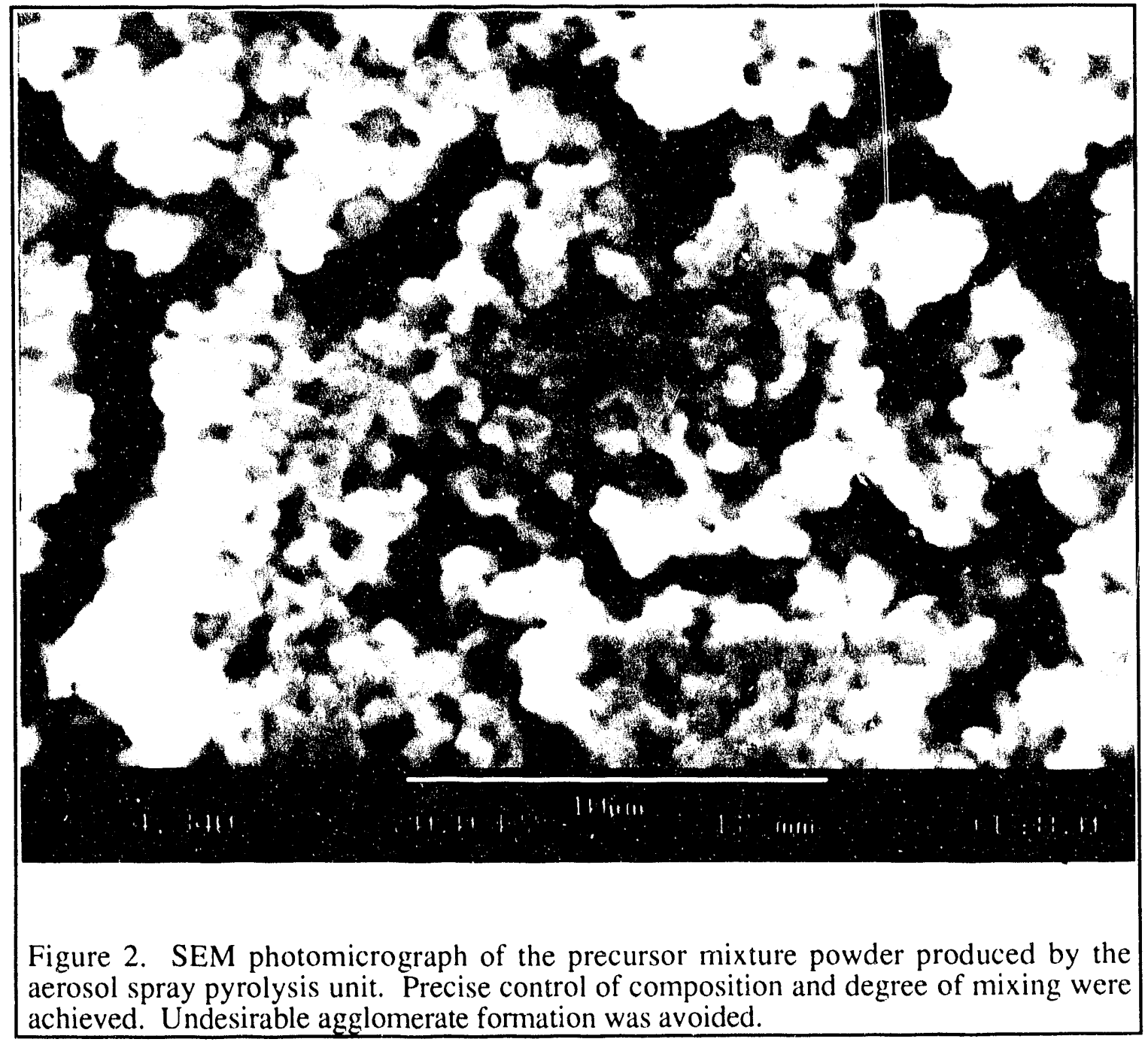

results of several experiments (in which the fuel-oxidizer ratio was systematically varied). It may be seen that each of the patterns corresponds to the cubic phase of yttria-stabilized $\mathrm{ZrO}_{2}$, and that no other phases were detected (sur $h$ as the tetragonal or monoclinic phases of $\mathrm{ZrO}_{2}$, or $\mathrm{Y}_{2} \mathrm{O}_{3}$ ). The target ceramic phase was thus synthesized using process temperatures several hundred degrees lower than those used in conventional processes--on sub-second time scales.

The crystallite size of the product material was shown to be 8-12 nanometers (nm), with an average size of $10 \mathrm{~nm}$. The crystallite size was determined using two characterization methods, each of which can be used to validate independently the values obtained with the other method. First, Figure 5 shows that each peak in each of the XRD patterns is quite broad--a clear indication that the average crystallite size is significantly below $100 \mathrm{~nm}$ in size. Analysis of the width at half-height of the peaks indicates a 
crystallite size of approximately $10 \mathrm{~nm}$. Second, Figure 6 shows the results of a selected area diffraction measurement. The continuous rings are indicative of very fine crystallites. Third, Figure 7 is a plot of BET surface area measurements for the same materials as in Figure 5. Recently, material that was prepared using $15 \%$ fuel had a (BET) specific surface area of $53 \mathrm{~m}^{2} / \mathrm{g}$ and an equivalent sphere diameter of $20 \mathrm{~nm}$.

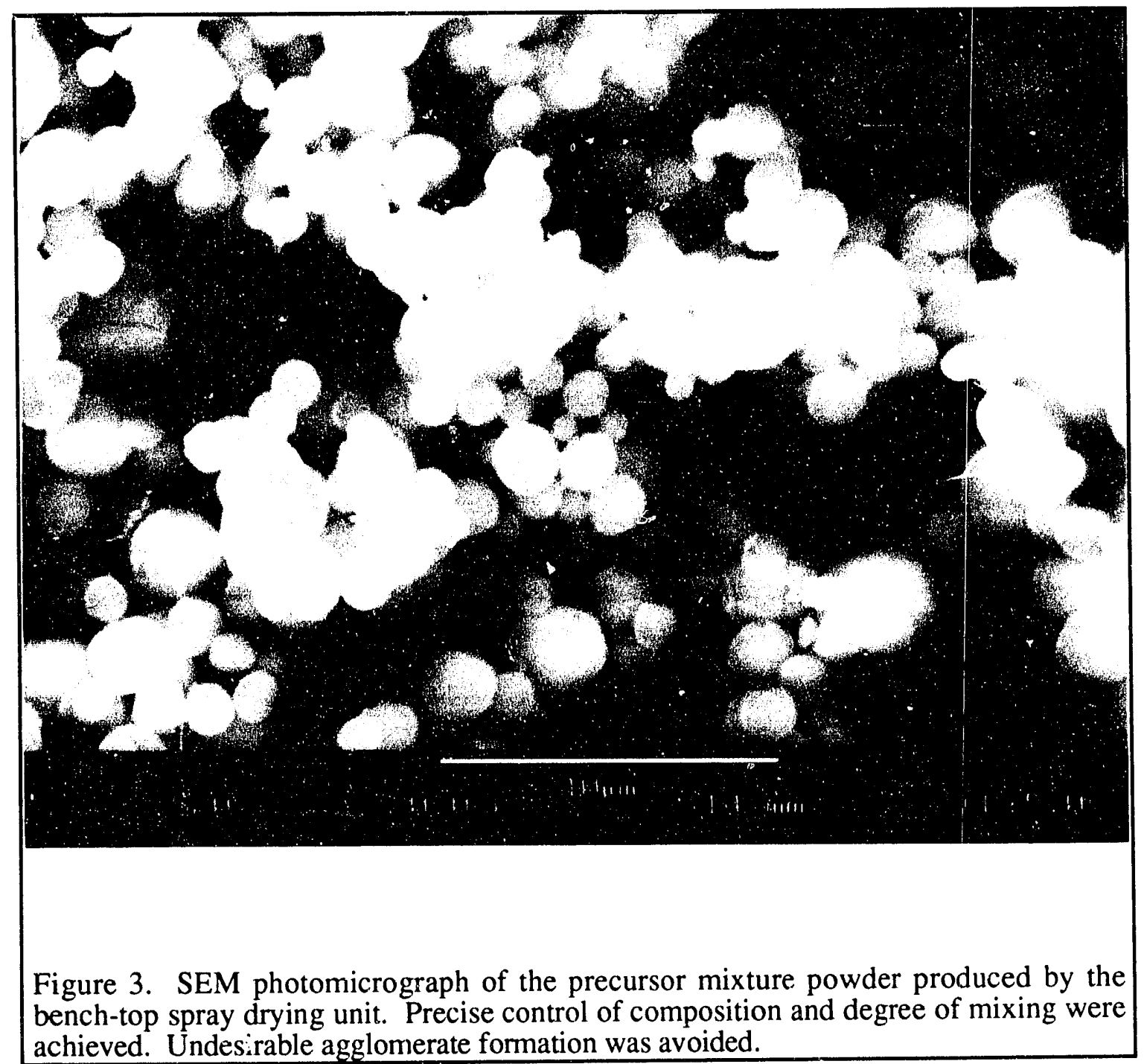




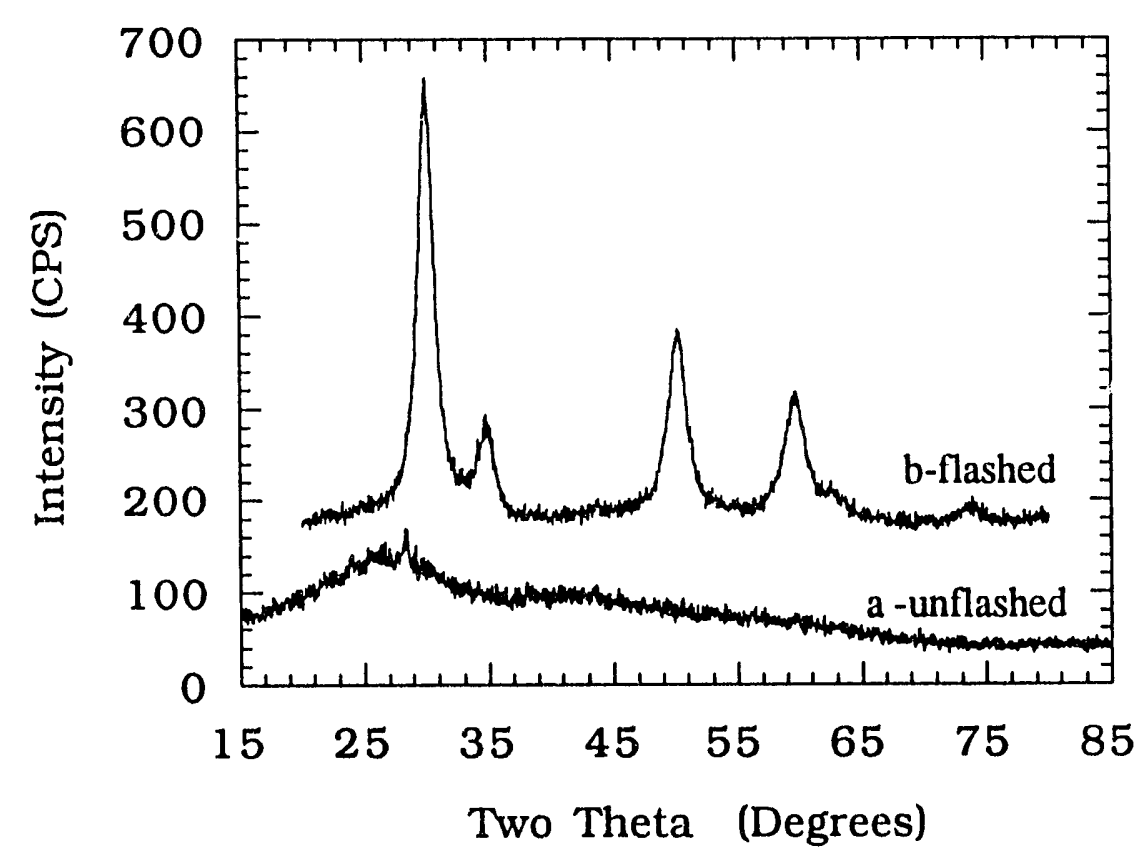

Figure 4. X-ray diffraction patterns of (a) the fuel-oxidizer precursor mixture prior to the combustion synthesis step, and (b) the product material following the combustion synthesis step. Conversion to the target ceramic material was complete.

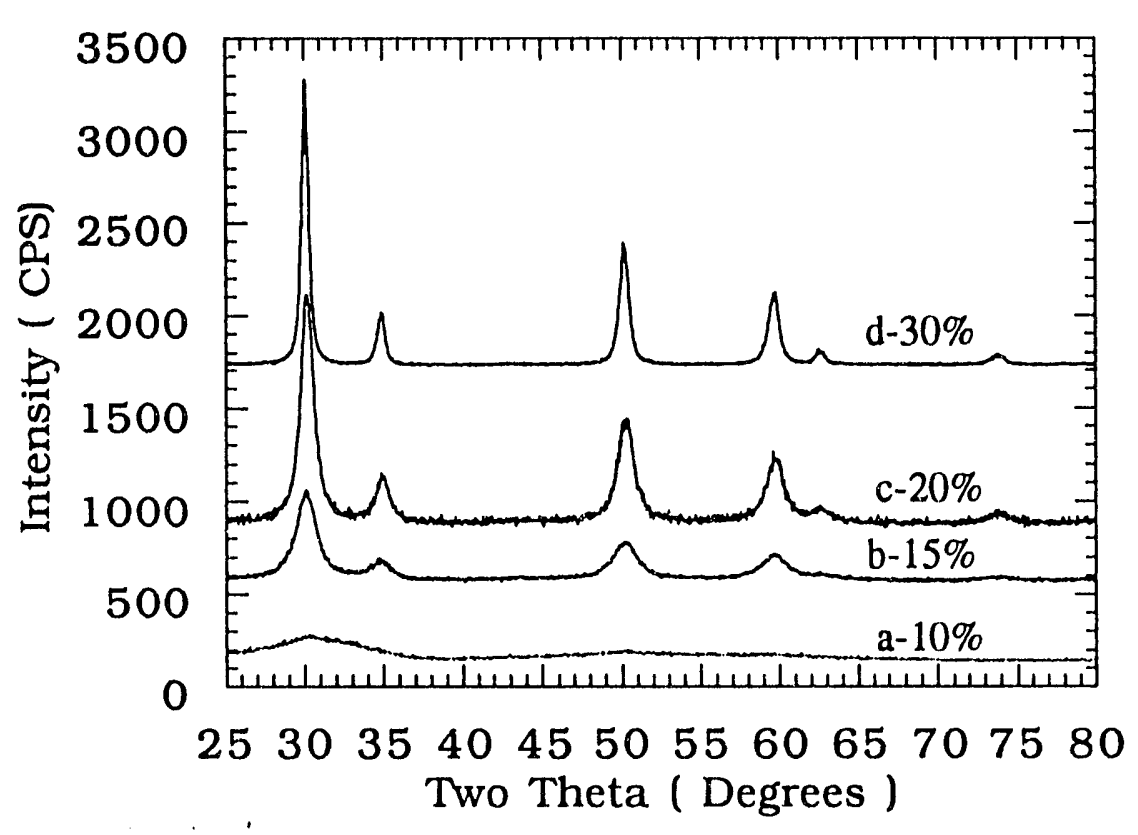

Figure 5. X-ray diffraction patterns of the combustion synthesis product material, prepared using different fuel-oxidizer ratios: (a) $10 \%$ fuel; (b) $15 \%$ fuel; (c) $20 \%$ fuel; and (d) $30 \%$ fuel. Each pattern is that for the cubic phase of yttria-stabilized $\mathrm{ZrO}_{2}$. The sigtificant peak broadening indicates that the average nanocrystallite size is $5.5 \mathrm{~nm}$. 







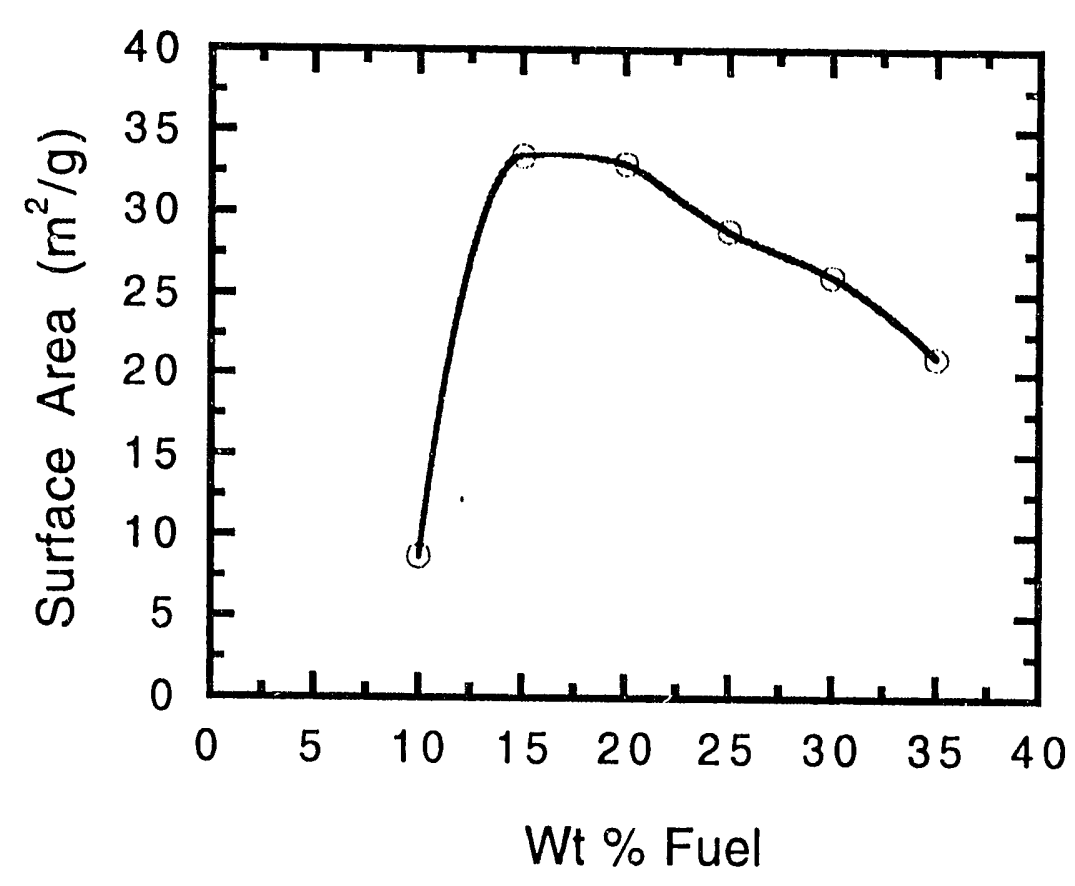

Figure 7. A plot of the BET specific surface area $\left(\mathrm{m}^{2} / \mathrm{g}\right)$ measurements for the combustion synthesis product material, prepared using different fuel-oxidizer raitos. The material that was prepared using $15 \%$ fuel has an equivalent sphere diameter of $30 \mathrm{~nm}$.

An explanation of the vigorous nature of the combustion synthesis reaction, and of the ability of the process to produce ultrafine, single-phase crystallites of the target material, was facilitated with the use of a theoretical model that was developed for the process. The model includes the appropriate transport equations to account for heat, mass and momentum transport processes that occur during the combustion synthesis process. Profiles of temperature, pressure, and gas- and solid-phase volume fractions are predicted. [See Figure 8.] The results clearly point to the fact that the driving force for selfpropagation is a unique combination of a high reaction enthalpy of the exothermic chemical reaction between fuel and oxidizer, and relative poor heat transfer conditions. The narrow, high-temperature combustion wave exists because the rate of heat generation exceeds the rate at which the heat is redistributed--internally by conduction to cooler regions of the sample and externally by radiation to the cooler surroundings. When the heat redistribution rate is low, a high local temperature may be briefly realized. The high local temperature leads to the rapid conversion of the precursor material to the target multicomponent oxide ceramic; the short time at temperature ( $<1$ second) is sufficient for product phase formation since the precursor mixture powder's high degree of mixing gives rise to extremely short diffusion distances in the reaction between fuel and oxidizer. 


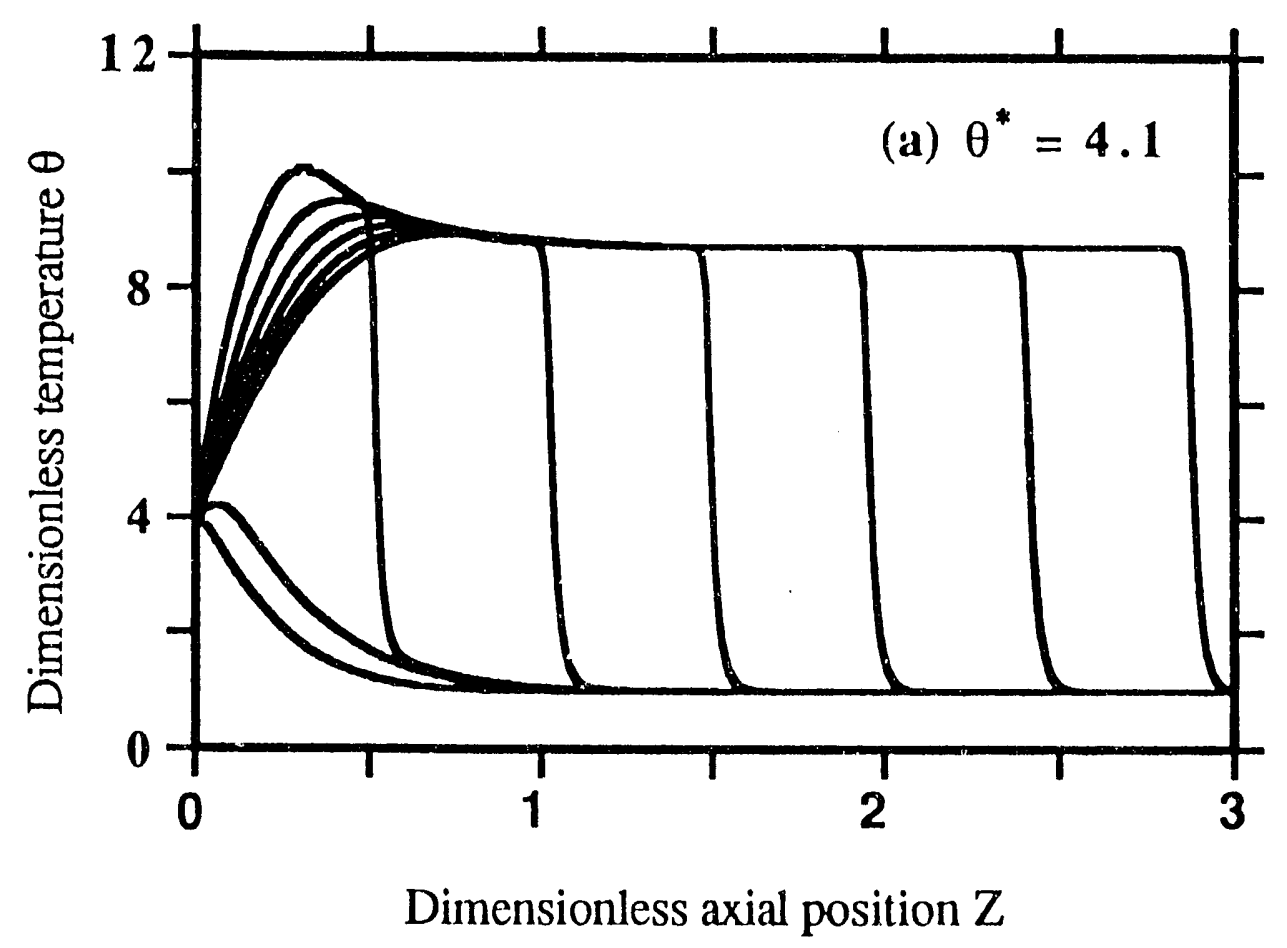

Figure 8. Typical temperature profile in a burning fuel-oxidizer mixture following ignition, as calculated using the theoretical model of the combustion synthesis process. A proper balance between the rates of heat generation and heat loss is essential for maintaining the combustion wave, thus ensuring the success of this process.

This combustion synthesis process step produced the cubic phase which, it should be noted, is generally considered to be the high-temperature phase (see Figure 9). This process step, however, is conducted using much lower temperatures and at ambient pressure (1 atm). This counterintuitive result can be explained by invoking the description of surfaces and interfaces according to classical thermodynamics. Surfaces, of course, have a characteristic surface energy. A curved surface may possess an even higher surface energy. This surface energy translates into, among other things, a pressure difference $(\Delta \mathrm{P})$ across the surface. [Capillary rise of a liquid in a tube is a familiar example that involves this pressure difference.] For curved surfaces, the following relationship holds: $\Delta \mathrm{P}=$ $2 \gamma / r$, where $\gamma$ is the surface tension and $r$ is the radius of curvature of the curved surface. Now, since this material is an oxide ceramic (where the surface tension is on the order of 1 $\mathrm{N} / \mathrm{m}$ ) and is highly curved (a diameter of $10 \mathrm{~nm}$, or $\mathrm{r}=5 \mathrm{~nm}$ ), the pressure difference across the particle surface is on the order of $300 \mathrm{MPa}$ or $45,000 \mathrm{psi}$. In other words, the pressure inside the nanoparticle is much higher than that of the ambient: tha high-pressure 


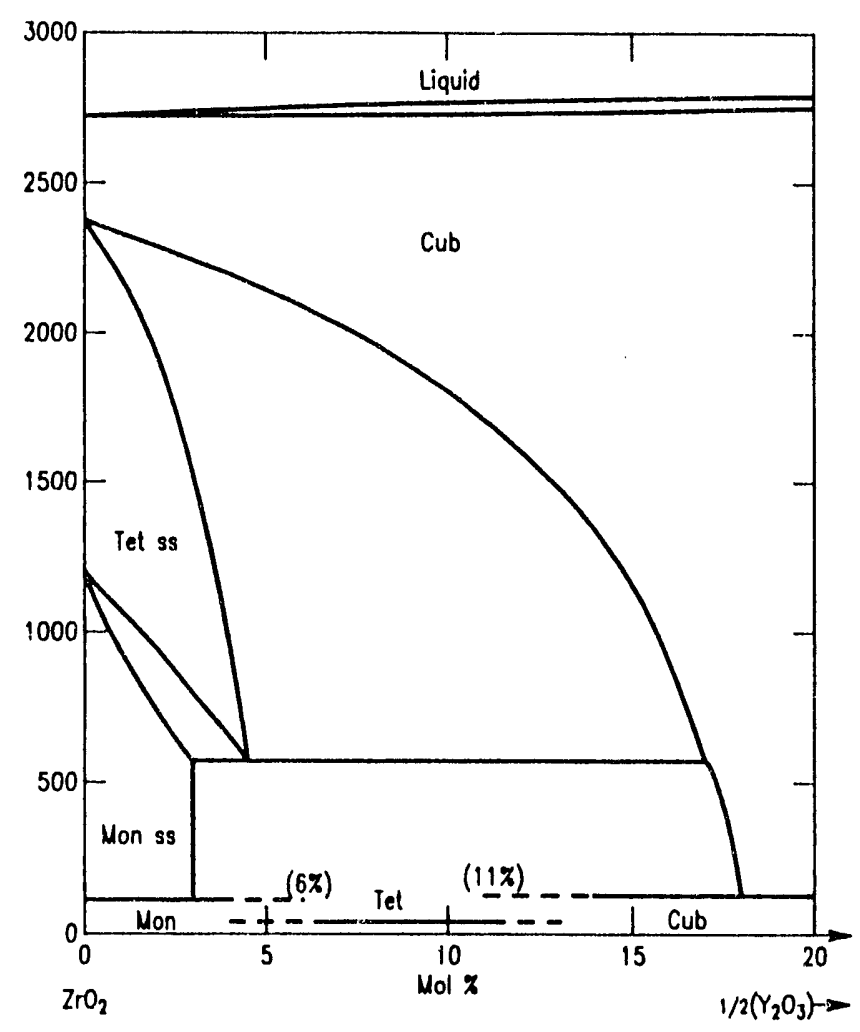

Figure 9. Phase diagram for the $\mathrm{Y}_{2} \mathrm{O}_{3}-\mathrm{ZrO}_{2}$ system. ${ }^{8}$ [P $=1$ atm.] The hightemperature phase was produced in this study, even though process temperatures were nearly $2000^{\circ} \mathrm{C}$ lower than required according to the phase diagram.

phase of yttria-stabilized $\mathrm{ZrO}_{2}$ exists at ambient pressure as a direct result of the material's nanometer-scale features.

\section{Fabrication of Dense Nanocrystalline $\mathrm{Y}_{2} \mathrm{O}_{3}$-Stabilized $\mathrm{ZrO}_{2}$ Parts}

The ultrafine, single-phase, yttria-stabilized $\mathrm{ZrO}_{2}$ thus produced was then used to prepare dense, nanocrystalline parts of the same material. The material was shaped into small pellets by one of the following methods: cold pressing, cold isostatic pressing or pressure filtration. Wet milling and centrifugation were in some cases used. Typical green densities were in the range of 30-39\% (by volume). Binders were not required. Fastfiring was conducted using one of two heating rates $\left(250\right.$ and $\left.500^{\circ} \mathrm{C} / \mathrm{min}\right)$ and maximum temperatures in the range of 1300 to $1400^{\circ} \mathrm{C}$. Dwell times were 2 minutes or less.

Preliminary experiments have demonstrated that fully dense yttria-stabilized $\mathrm{ZrO}_{2}$ can be prepared from the nanocrystalline powders that were prepared in the previous process step. Figure 10 shows the effect of heating rate and firing temperature on the final density of the densified part. For example, with a soak time of only 2 minutes, a final 


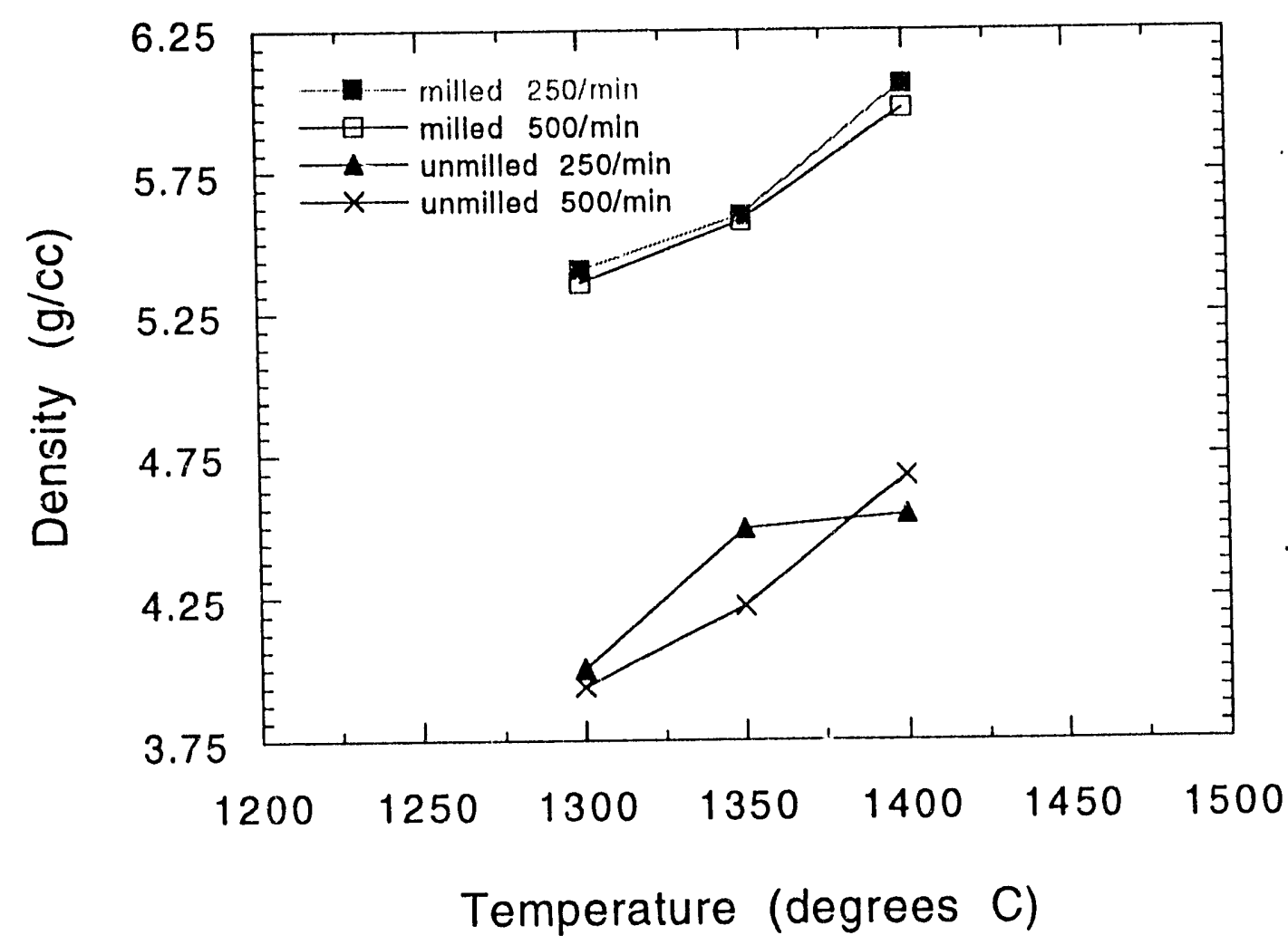

Figure 10. Densification behavior of yttria-stabilized $\mathrm{ZrO} 2$ unver fast firing conditions. The effect of heating rate and firing temperature on the final density of the densified part is shown. Note that energy-efficient firing times are 2 minutes or less.

density of about $99 \%$ of theoretical density was achieved at $1400^{\circ} \mathrm{C}$. These preliminary findings are encouraging--particularly when it is noted that the green density of this part was only $39 \%$. This of course points to the strong need for achieving a high and uniform green density. Further increases in green density should allow fast firing to proceed at temperatures as low as $1200^{\circ} \mathrm{C}$ when the same heating rates and dwell times are used.

Preliminary results also indicate that nanocrystalline features were retained--even at full density. Figure 11 is an SEM photomicrograph of a sample that had been densified to full density, using a $500^{\circ} \mathrm{C} / \mathrm{min}$ heating rate, and held at $1400^{\circ} \mathrm{C}$ for 2 minutes. The sample had been cut, polished and etched thermally. IIt should be noted that, as this report was finalized, good photographic contrast was not achieved in the preparation of Figure 11. The fine features in the samples are at the lower limit of the resolution of the microscope that was used to image the sample. At this length scale, the performance of the microscope degrades precipitously.] The grain size was determined to be $200 \mathrm{~nm}$. In addition, Figure 12 shows that samples fired at $1300^{\circ} \mathrm{C}$ remained single-phase yttria- 


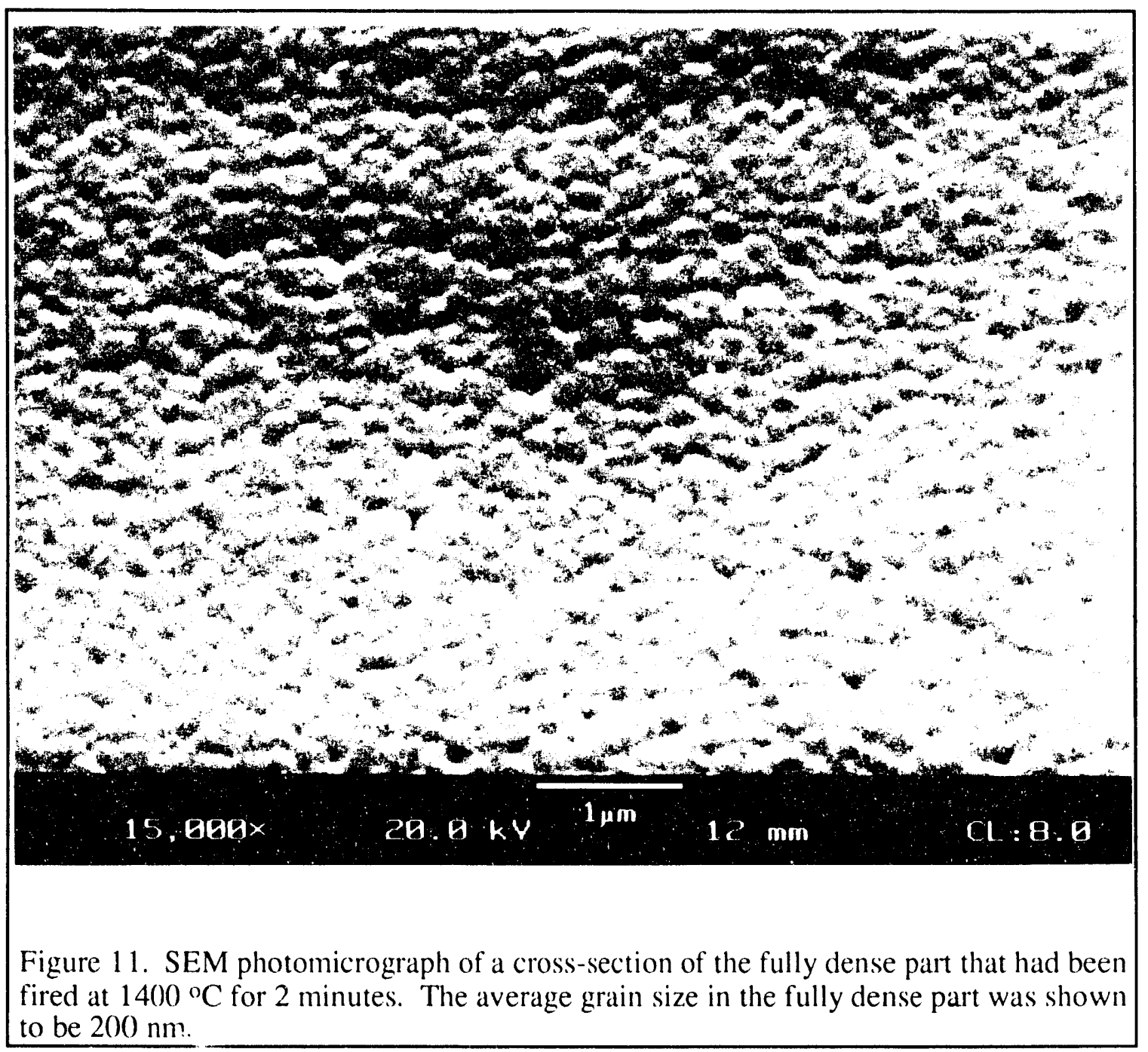

stabilized $\mathrm{ZrO}_{2}$. Dense, nanocrystalline, single-phase samples were thus successfully prepared.

The preliminary results are important since it was shown that good densification was achieved using sintering temperatures and times much lower than those used for sintering conventional powders used in fast firing. The process appears to be able to produce a dense ceramic part, retain a fine grain size and also reduce processing temperature. Significant energy savings are thus realized.

The reason that low porosity and fine grain size can be achieved simultaneously may be understood as follows. ${ }^{79}$ First, if the goal of fine grain size and high density is chosen, the choice of a very fine powder is dictated. Such a powder effectively represents a large supply of available energy in the form of particle surface energy. Second, for a sintering process to be effective in producing a very small final grain size, it must convert 


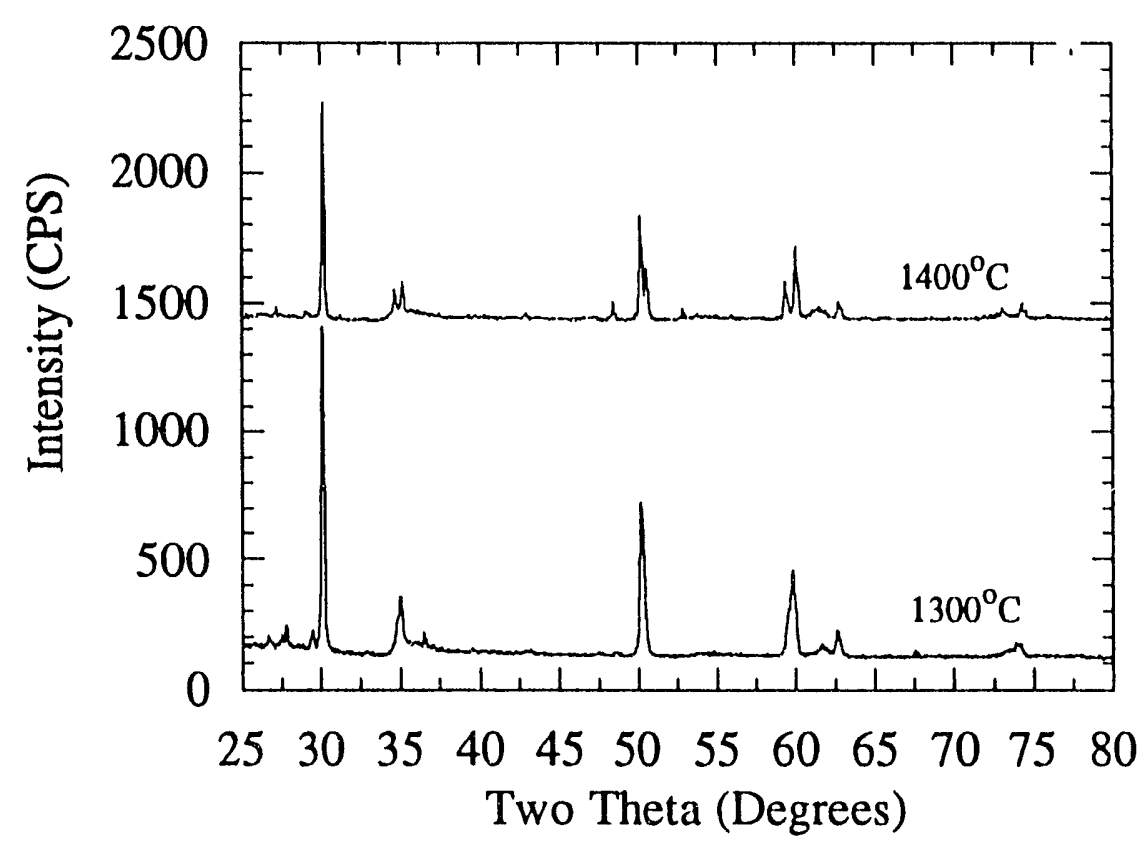

Figure 12. XRD pattern of the fully dense part that was shown in Figure 11. The pure and homogeneous single-phase yttria-stabilized $\mathrm{ZrO}_{2}$ was retained in the sample fired at $1300^{\circ} \mathrm{C}$.

the surface energy into the promotion of densification rather than grain growth. The literature has shown that in many systems the densification process has a much higher activation enthalpy than grain coarsenıng. This fact suggests that for highly-energetic fine particles, the furnace temperature profile must quickly move the green shape to a temperature where densification can progress more rapidly than grain coarsening. This tactic is demonstrated in Figure 12. One must, therefore, (i) heat the sample as quickly as possible in order to bypass the "low temperature grain growth region;" (ii) maintain the sample in the "high temperature densification region " just long enough to eliminate porosity without much concommittent grain growth; and (iii) cool the sample rapidly to a lower temperature at which (additional) grain growth cannot occur.

These results represent a significant improvement over the results of other methods used to produce dense nanocrystalline materials. The processing equipment is not specialized, expensive or energy intensive. The processing sequence is also applicable to increased production volume of both powder and parts. [In addition, preliminary discussions have been held with colleagues in manufacturing firms. Their response has been quite positive.] 


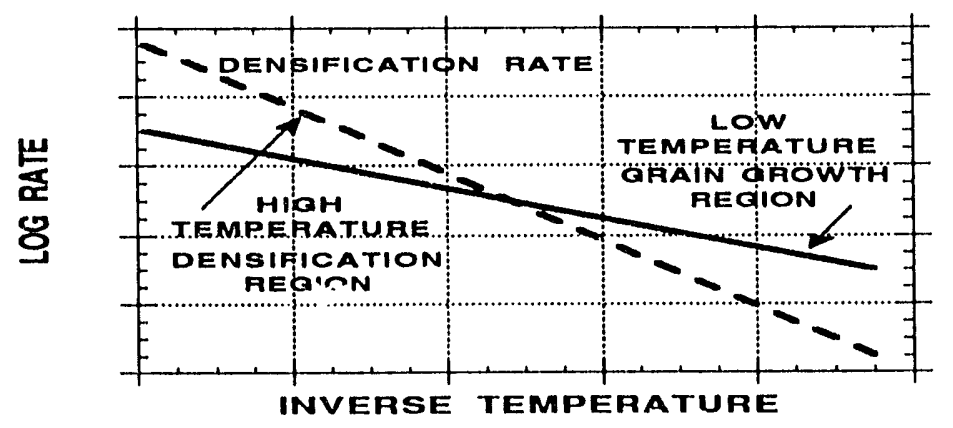

Figure 13. The rates of densification and grain growth as a function of temperature. The goal of fast-firing is to take the sample into and out of the "high temperature densification region" as quickly as possible. This strategy, when conducted properly, results in samples that are fully dense and nanocrystalline.

\section{Prospects for Scale-up, Energy Savings, Commercialization Potential}

Scale-up of this process is expected to be smooth and straightforward. In the present embodiment of the process, a spray drying unit with a 4 -in.-diameter $(0.33$-ft.diameter) drying chamber is used. Commercially available spray drying units measuring as large as 18 feet in diameter are available ${ }^{10}$ Nanoparticle production rates on the order of kilograms per hour are expected to be easily achieved. [This figure should be compared with the nanogram to milligram per hour quantities that are produced by existing methods.] Similarly, since the combustion synthesis merely requires low-temperature, ambientatmosphere equipment, no difficulties are foreseen in scaling-up this process step. Finally, fast-firing process step has already been scaled up in at least one of the so-called "lowertech" ceramics industries: whitewares (plates and bowls) and other clay-based ceramics. ${ }^{9}$ Again, precedent exists that suggests that scaling up the fast-firing process step should be successful and easily achieved. In addition, the equipment is in each case simple to operate--so that very little operator training is required.

The energy savings will be quite significant. First, particle synthesis simply requires using the functional equivalent of a $300^{\circ} \mathrm{C}$ hot plate, where sub-second synthesis times are all that is required. High-temperature, high-vacuum (that is, high-capital and high-operating cost) equipment is not required. Second, the reduction in processing temperature and processing time should also result in considerable energy savings. For example, if a normal sintering process is considered to take at least one hour and the heating rates are in the order of $100^{\circ} \mathrm{C} / \mathrm{hr}$, the product is exposed to high temperature for 8 to 10 hours. The current fast fire profile only exposes the product to high temperature for 
about 6 minutes ( 0.1 hours). This reduction in exposure time suggests an energy savings between a factor of 10 and 100 if the major energy consumption is considered to be furnace heat loss. Simultaneous reduction in processing temperature will also affect this calculation in an even more favorable manner.

In short, commercialization of this process is expected to be easily achieved, for the following reasons.

- The process uses equipment that is available "off the shelf," and that can be used either directly or with only minor modifications.

- The equipment can be used properly by personnel following brief training.

- The process is easily "re-tooled" by simply washing the equipment and feeding a new precursor solution to the spray drying unit. Such a conversion could be accomplished in less than an hour. Dozens of product materials could be produced.

- Fast-firing has already been shown to work well in large-scale ceramics processing operations.

- Significant energy savings are realized at every step in the process.

IV. REFERENCES CITED

1. Research Opportunities for Materials with Ultrafine Microstructures, National Materials Advisory Board report NMAB-454, National Academy Press (1989).

2. Multicomponent Ultrafine Microstructures, L. E. McCandlish, D. E. Polk, R. W. Siegel, and B. H. Kear, eds., MRS Symp. Proc.,vol. 132 (1989).

3. Rabinowitz, M., H. W. Arrowsmith and S. D. Dahlgren, "Dependence of Maximum Trappable Field on Superconducting $\mathrm{Nb}_{3} \mathrm{Sn}$ Cylinder Wall Thickness," Appl.

Phys. Lett., 30, 607-609 (1977).

4. Gleiter, H., "Nanocrystalline Materials," Progress in Materials Science, 33, 223-315 (1989).

5. Nanophase and Nanocomposite Materials, S. Komarneni, J. C. Parker and G. J. Thomas, eds., MRS Symp. Proc., vol. 286, Materials Research Society, Pittsburgh, PA (1982).

6. Shreve, R. N. and J. A. Brink, Chemical Process Industries, 4th ed., McGraw-Hill, New York (1977).

7. Wu, W. and R. J. Brook, Trans. J. Br. Ceram. Soc., 82 [6], 200-205 (1983).

8. Phase Diagrams for Ceramists, Vol VI, R. S. Roth, J. R. Dennis and H. F. McMurdie, eds., American Ceramic Society, Westerville, OH (1987).

9. Ghorra, G. J., "Theory of Fast Firing," Ceram. Eng. Sci. Proc., 14[1-2], 77-115 (1993). 
10. Perry, R. H. and C. H. Chilton, Chemical Engineers' Handbook, 5th ed., McGrawHill, New York (1973).

\section{LIST OF PERSONNEL}

Gregory C. Stangle, Assistant Professor (PI/PD)

Vasantha R. W. Amarakoon, Associate Professor (PI)

Walter A. Schulze, Professor (PI)

K. R. Venkatachari, Postdoctoral Research Associate

Huang Dai, Graduate Research Assistant

Steve Ostrander, Graduate Research Assistant

Amin Abid, Graduate Research Assistant 

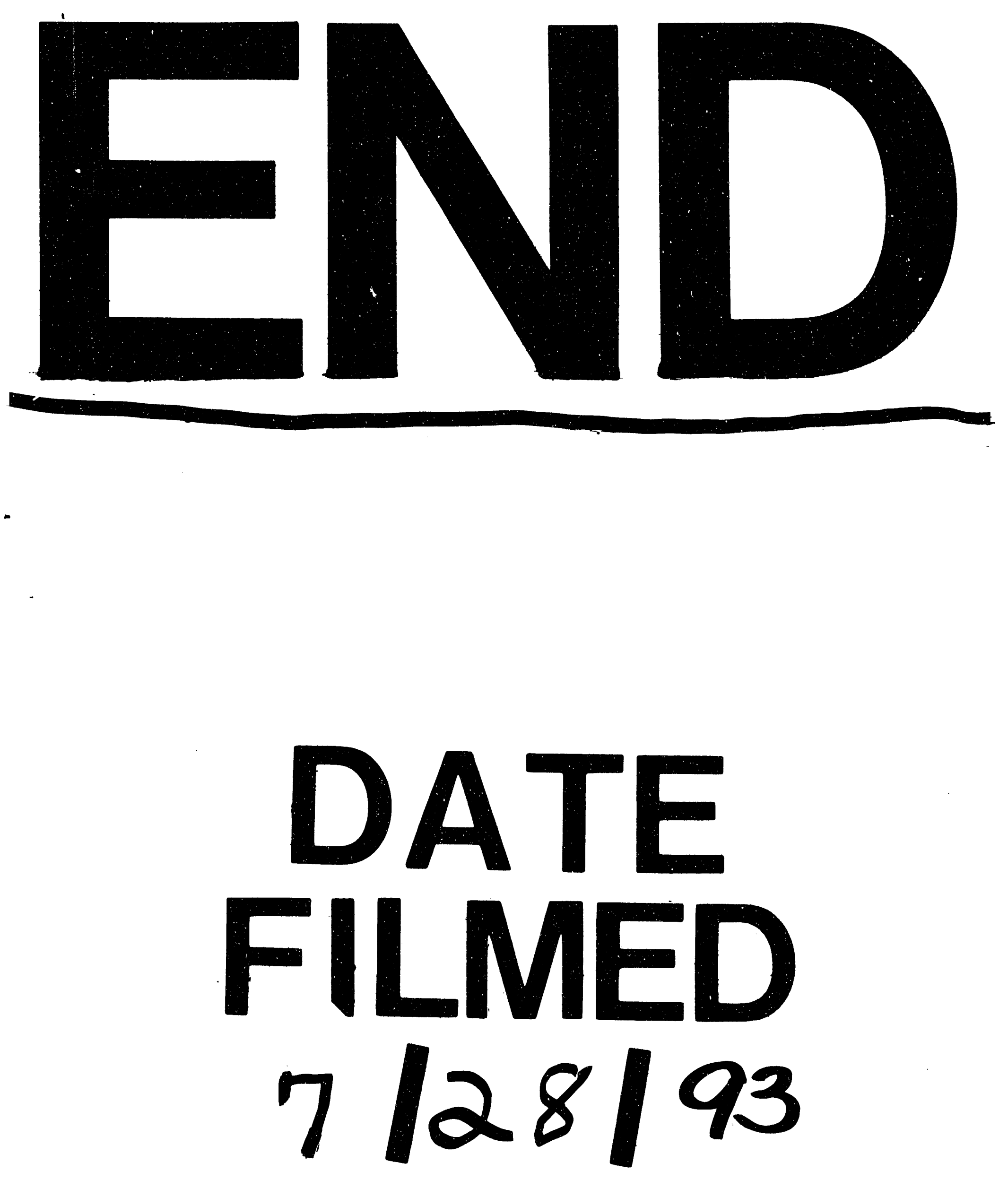
